\title{
CARBONATO DE CÁLCIO OU CÁLCIO QUELADO? ELUCIDANDO ESSA DÚVIDA POR MEIO DE ESTUDO DE CASO
}

\author{
Adriana Nori de Macedo ${ }^{\mathrm{a}}$, Mariana Ramos Almeida ${ }^{\mathrm{a}}$ e Ana Luiza de Quadros $, *,(1)$ \\ a'Departamento de Química, Instituto de Ciências Exatas, Universidade Federal de Minas Gerais, 31270-901 Belo Horizonte - MG, \\ Brasil
}

Recebido em 11/09/2020; aceito em 30/11/2020; publicado na web em 03/02/2021

\begin{abstract}
CALCIUM CARBONATE OR CALCIUM CHELATE? ELUCIDATING THIS QUESTION USING A CASE STUDY. Analytical Chemistry disciplines are present in the curriculum of several undergraduate courses. However, based on our experience, students not always are able to realize the association of the scientific concepts included in these disciplines with the social context and, specially, with their future field of work. In the present report, we used a case study about calcium supplementation by calcium carbonate and calcium chelate that included a science outreach activity, which was applied to students enrolled in three undergraduate courses: Pharmacy, Biomedicine, and Chemistry. We noticed that students not only got actively involved with the case, but also highlighted the importance of this activity, took the case beyond the classroom, and requested the inclusion of other similar activities in the discipline. Although different answers were presented for the case, the results obtained bring a positive impact on the instructors' teaching practice and on the courses as a whole.
\end{abstract}

Keywords: case study; Analytical Chemistry; high education; calcium supplementation.

\section{INTRODUÇÃO}

A Química Analítica está presente nos currículos dos cursos superiores de Química e em vários outros cursos de graduação, geralmente com um caráter mais formal ou tecnicista. Com isso, nem sempre o estudante é capaz de perceber os inúmeros usos práticos dos conhecimentos contidos nas ementas dessa disciplina. ${ }^{1}$ Como consequência, um dos grandes desafios de professores tem sido fazer com que os estudantes percebam a estreita relação dos conhecimentos desenvolvidos nessas disciplinas com o contexto social ou com o campo de trabalho futuro.

Em função de reorganizações curriculares, a carga horária das disciplinas de Química Analítica tem diminuído gradualmente, mas, em muitos casos, o conteúdo desenvolvido continua extenso. Com isso, é imprescindível que se utilize de estratégias para tornar os processos de ensino e de aprendizagem mais eficientes. Tanto a Química Analítica qualitativa quanto a quantitativa possuem um papel relevante na formação do Químico e dos profissionais de áreas correlatas, já que possibilitam a aquisição de uma vasta gama de conhecimentos envolvendo o entendimento e o desenvolvimento de métodos para a determinação da composição química de amostras.

Este trabalho foi desenvolvido na Universidade Federal de Minas Gerais (UFMG), junto a duas disciplinas ligadas à Química Analítica - Análise Quantitativa e Química Analítica - oferecidas aos cursos de Química e aos cursos de Farmácia e Biomedicina, respectivamente, as quais usaram o método de estudo de caso como estratégia para que os estudantes melhorem a percepção da aplicação/importância dos conhecimentos nelas trabalhados. $\mathrm{O}$ estudo de caso utilizado envolveu a suplementação de cálcio a partir de carbonato de cálcio ou cálcio quelado.

O ensino por meio do uso de Estudos de Caso tem como base teórica o construtivismo e considera uma intensa interação entre os sujeitos (estudantes, professor), o ambiente, os materiais e o conteúdo. ${ }^{2}$ Os estudos de caso são baseados na descrição de uma situação que, geralmente, envolve uma decisão, um desafio, uma

*e-mail: aquadros@qui.ufmg.br oportunidade ou um problema a ser enfrentado por uma pessoa ou por um grupo de pessoas. ${ }^{3}$ Ao usar os estudos de caso no ensino é possível fazer um ensaio de como pensar profissionalmente e, com isso, instigar estudantes a usar conceitos científicos para lidar com um problema prático. ${ }^{4}$ Os estudos de caso no Ensino Superior brasileiro têm sido usados na área de saúde, ${ }^{5}$ nas engenharias, ${ }^{6}$ em cursos de Química $^{7-9}$ e, ainda, encontramos propostas de uso de estudos de caso específicas para a Química Analítica. ${ }^{10}$

Este trabalho foi desenvolvido com o objetivo de analisar o envolvimento dos estudantes com a atividade proposta, o desenvolvimento de algumas habilidades, tais como o trabalho em equipe e a divulgação científica, e, ainda, a relação que fazem do caso em estudo com os conceitos científicos presentes na disciplina.

\section{Suplementos de cálcio, biodisponibilidade e dosagem}

O cálcio é um dos minerais mais importantes para a saúde humana e também o mais abundante, correspondendo a cerca de 1 a $2 \%$ da massa corporal de um adulto. ${ }^{11}$ Trata-se de um nutriente essencial, pois além de sua função estrutural na formação e manutenção dos ossos e dentes, também está envolvido nos processos de contração muscular (movimentação do corpo e batimentos do coração), coagulação sanguínea e transmissão de impulsos nervosos, entre outras funções. ${ }^{11,12}$ As principais fontes de cálcio são o leite e seus derivados, sendo ele também encontrado, em menores quantidades, em frutas, vegetais, cereais, carne, peixe e ovos. ${ }^{11,13}$ Em geral, a suplementação de cálcio é indicada para pessoas que não conseguem obter os níveis recomendáveis para esse nutriente através da alimentação. É muito comum a prescrição desses suplementos para indivíduos que sofrem de osteopenia ou osteoporose, idosos e mulheres a partir dos 50 anos, por serem os grupos mais suscetíveis a perdas ósseas e fraturas..$^{14,15}$

Os suplementos de cálcio podem ser apresentados de diversas formas, como, por exemplo, carbonato de cálcio, citrato de cálcio, cálcio de ostras e o chamado "cálcio quelado", também conhecido como "cálcio quelato". No Brasil, os sais mais comumente utilizados nos suplementos são o carbonato de cálcio e o citrato de cálcio. ${ }^{16}$ Apesar de serem bem tolerados pela maioria das pessoas, há relatos 
de alguns efeitos colaterais, incluindo constipação intestinal, inchaço abdominal e flatulência, principalmente associados ao uso do carbonato de cálcio. ${ }^{14}$ Já o chamado "cálcio quelado" consiste em formulações contendo complexos de cálcio com aminoácidos que buscam diminuir esses efeitos colaterais, além de aumentar a biodisponibilidade e a estabilidade do suplemento. ${ }^{17}$ Diferentes tipos de aminoácidos podem ser utilizados, mas a glicina (Gly) é a mais comum, por ser de tamanho menor e pela sua habilidade de formar complexos estáveis com proporção 1:2 do cátion metálico em relação ao ligante. ${ }^{17}$

A biodisponibilidade refere-se à fração de uma substância que é absorvida e entra na circulação. Os mecanismos de absorção mineral a partir da dieta ou de suplementos alimentares são complexos e afetados por várias circunstâncias, como sexo, idade, saúde gastrointestinal, saúde em geral e ingestão simultânea de alimentos contendo substâncias inibidoras, competidoras ou melhoradoras de biodisponibilidade. ${ }^{17}$ Apesar dessa grande gama de circunstâncias que afetam a absorção dos minerais, estudos têm reportado uma biodisponibilidade média de cerca de $24 \%$ para o cálcio ingerido na forma de carbonato de cálcio, enquanto esse valor é de $44 \%$ para o "cálcio quelado", referindo-se ao bisglicinato de cálcio, cuja fórmula estrutural está representada na Figura 1. ${ }^{17,18}$ Observa-se que a biodisponibilidade do carbonato de cálcio aumenta para cerca de $30 \%$ quando ele é ingerido junto a uma refeição, enquanto a absorção do bisglicinato de cálcio não é efetivamente alterada por esse fator. ${ }^{18}$ Essa observação tem sido associada à maior estabilidade do quelato, que chega intacto ao intestino, apresenta menor tendência de reagir com outras substâncias ingeridas e pode ser absorvido em sua forma original pelas células intestinais, não competindo com outros minerais pelo transporte de íons através da membrana celular. ${ }^{17}$

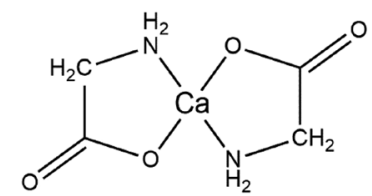

Figura 1. Fórmula estrutural do bisglicinato de cálcio. ${ }^{19,20}$

Os valores de ingestão diária de cálcio (IDR) recomendados podem variar entre países. ${ }^{16}$ No Brasil, a Agência Nacional de Vigilância Sanitária (ANVISA) recomenda a ingestão de $1000 \mathrm{mg}$ de cálcio por dia para adultos, independentemente da faixa etária. ${ }^{21}$ O Instituto de Medicina dos Estados Unidos também recomenda a ingestão de $1000 \mathrm{mg}$ de cálcio por dia para adultos, porém, aumenta para $1200 \mathrm{mg} /$ dia para mulheres acima dos 50 anos e homens acima dos 70 anos. ${ }^{22}$ Entretanto, observa-se que a dosagem prescrita de suplementos de cálcio frequentemente fica abaixo de $500 \mathrm{mg} / \mathrm{dia}$, considerando que a dieta também é fonte de cálcio, cuja ingestão excessiva não é benéfica, podendo causar hipercalcemia (excesso de cálcio no sangue), hipercalciúria (excesso de cálcio na urina), calcificação de tecidos moles, cálculos renais, câncer de próstata, interferência na absorção de ferro e zinco e constipação intestinal. ${ }^{14,22}$ A fim de evitar esses problemas, o Instituto de Medicina dos Estados Unidos recomenda o limite máximo tolerável de $2500 \mathrm{mg}$ de cálcio por dia para adultos entre 19 e 50 anos, diminuindo para $2000 \mathrm{mg} /$ dia para indivíduos acima dos 50 anos. ${ }^{22}$

\section{Conceitos explorados no estudo de caso}

No estudo de caso proposto, os conceitos explorados com os alunos foram estequiometria da reação, formação de íons complexos, equilíbrio e volumetria de complexação. Nossa experiência tem mostrado que, de forma geral, os alunos têm dificuldade na interpretação e na resolução de problemas que envolvem cálculos estequiométricos, uma vez que não conseguem perceber a relação desse assunto com aspectos do cotidiano. Dessa forma, explorar esse conceito em um estudo de caso pode ser uma estratégia interessante para construir essa relação.

A compreensão dos equilíbrios químicos é importante para o entendimento de diferentes aspectos da transformação de substâncias químicas em, por exemplo, processos industriais, biológicos e ambientais. O tema equilíbrio químico é recorrente em diversas disciplinas de Química, tanto no nível qualitativo quanto no quantitativo. ${ }^{23} \mathrm{O}$ equilíbrio de complexação envolve o estudo de íons metálicos que formam complexos por meio de ligações covalentes com moléculas chamadas de ligantes. As moléculas que possuem um par de elétrons livre podem atuar como ligantes. Essas moléculas devem ser estáveis como moléculas livres, podendo ter carga ou serem neutras.

No ensino de equilíbrio de complexação são abordados os conceitos de ácidos e bases de Lewis. ${ }^{24} \mathrm{O}$ átomo metálico central é um aceptor de pares de elétrons, ou seja, desempenha o papel de ácido de Lewis. Os ligantes podem ser considerados bases de Lewis, uma vez que são doadores de pares de elétrons. Muitos ligantes são bases de Bronsted, podendo ser afetados pelas mudanças de pH no meio. Os ligantes podem ser mono ou polidentados. Os ligantes monodentados possuem um grupo doador e os polidentados mais de dois grupos disponíveis para a coordenação. Os ligantes polidentados formam complexos mais estáveis que os análogos monodentados, devido ao efeito quelado. Esses ligantes são chamados de quelantes. Muitos exemplos de complexos estão presentes no meio biológico, como a hemoglobina ( $\mathrm{Fe})$, a vitamina B12 (Co) e a clorofila (Mg).

Os métodos volumétricos são um grupo de procedimentos empregados na análise quantitativa para determinar a concentração de um componente de uma amostra. Esses métodos são baseados na medida de volume de um reagente de concentração conhecida a partir de uma reação química com a amostra. Os métodos volumétricos geralmente são desenvolvidos nas disciplinas que inserem os estudantes de graduação em laboratórios de Química. O ensino desses métodos é importante para o aprendizado de conceitos como equilíbrio químico, $\mathrm{pH}$, solução tampão, preparo de amostra e tratamento estatístico de dados químicos. A volumetria é tradicionalmente considerada como um método primário de análise e é muito utilizada para validar outros métodos secundários.

A complexometria (volumetria de complexação - aplicação do equilíbrio de complexação) foi descrita pela primeira vez em 1946, quando a titulação de cálcio e magnésio com EDTA (ácido etilenodiaminotetracético) foi relatada e a "murexida" foi empregada como o primeiro indicador metalocrômico. ${ }^{25}$

O ácido etilenodiaminotetracético (EDTA) é amplamente utilizado como ligante na Química Analítica, pois forma complexos com estequiometria 1:1 com a maioria dos íons metálicos. ${ }^{26} \mathrm{O}$ ácido neutro é tetraprótico e é frequentemente indicado como $\mathrm{H}_{4} \mathrm{Y}$. O emprego da volumetria de complexação tornou-se importante em diversos segmentos da indústria. O EDTA não é só interessante em termos químicos, como também é utilizado comercialmente no tratamento de casos de envenenamento por metais pesados e como ingrediente de preservação de alimentos e como aditivo para xampus. ${ }^{27}$

A volumetria de complexação empregando o EDTA é um tópico geralmente ensinado nas disciplinas de Química Analítica da graduação. Os exemplos mais empregados são o da determinação da dureza total da água e o da análise de cálcio em suplementos alimentares usando o negro de eriocromo $\mathrm{T}$ ou a calmagita como indicadores visuais de ponto final. 
Na determinação de cálcio em suplementos, o ácido etilenodiaminotetracético (EDTA) é usado como titulante que complexa os íons $\mathrm{Ca}^{2+}$ presentes no suplemento. Como a solução de EDTA e o complexo formado com o cálcio não são coloridos, o ponto final da titulação é detectado visualmente adicionando um indicador metalocrômico, frequentemente o negro de eriocromo $\mathrm{T}$, à amostra a ser analisada. ${ }^{28}$ A mudança de cor ocorre quando o indicador passa de sua forma complexada a íons metálicos (coloração vinho) para a forma livre (não complexada), que apresenta coloração azul em pH 10.

A mudança de cor sinaliza o ponto final, pois ocorre quando o EDTA, depois de complexar todos os íons $\mathrm{Ca}^{2+}$ não ligados, remove o íon $\mathrm{Ca}^{2+}$ ligado ao indicador. A remoção é possível apenas porque o EDTA complexa o $\mathrm{Ca}^{2+}$ mais fortemente do que o indicador. Esse resultado pode ser usado para abordar a formação de íons complexos enfatizando a competição de diferentes agentes complexantes pelo mesmo íon metálico com os valores de suas respectivas constantes de formação $\left(\mathrm{K}_{\mathrm{f}}\right)$ de complexos. ${ }^{28}$

Outro aspecto que pode ser discutido é o valor do $\mathrm{pH}$ da solução. A reação de complexação dos íons $\mathrm{Ca}^{2+}$ com o EDTA se dá de forma completa quando o ligante se encontra na forma desprotonada $\left(\mathrm{Y}^{4-}\right)$. Para garantir que o titulante esteja em sua forma completamente desprotonada, os valores de $\mathrm{pH}$ precisam ser maiores que 12 , de acordo com o gráfico de distribuição das espécies. ${ }^{26}$ Nessas condições, a constante de formação correspondente é $5,01 \times 10^{10}{ }^{28}$ No entanto, nesse valor de $\mathrm{pH}$ ocorre a precipitação dos íons $\mathrm{Ca}^{2+} \operatorname{como} \mathrm{Ca}(\mathrm{OH})_{2}$, o que impede que a titulação seja realizada em valores de $\mathrm{pH}$ tão alto.

Em vez disso, a titulação dos íons $\mathrm{Ca}^{2+}$ é realizada em $\mathrm{pH} 10$, usando um tampão amoniacal. No entanto, nesse valor de $\mathrm{pH}$, uma fração do EDTA se encontra na forma $\mathrm{HY}^{3-}$, e a constante de formação condicional nesse $\mathrm{pH}$ é $1,8 \times 10^{10} .{ }^{28}$ Devido a essa alta constante de formação, o complexo apresenta grande estabilidade, o que leva a pontos finais nítidos.

$\mathrm{Na}$ literatura são encontradas várias propostas para experimentos práticos envolvendo volumetria de complexação para cursos de Química Analítica. ${ }^{1927-30}$ Neste trabalho nossa atenção se dirigiu para atividades que possam levar os estudantes a perceber algumas aplicações desses conceitos.

\section{METODOLOGIA}

Ao usar um Estudo de Caso, o professor não fornece as informações ou os produtos da Ciência, mas age como um orientador, desafiando e envolvendo os estudantes em um caso que exige interação com o conteúdo. Não se trata de método de ensino inovador, mas que pode trazer contribuições para o envolvimento dos estudantes com um caso específico e a consequente inserção de conceitos científicos.

Com base nesse entendimento, optamos por fazer uso de estudos de caso no ensino superior. Partimos da hipótese de que se trata de uma oportunidade promissora de construir, junto aos estudantes, a ideia da direta relação entre os conceitos científicos e a atividade profissional futura.

Essa experiência com estudo de caso foi realizada em duas turmas de graduação, da UFMG, no segundo semestre de 2019. Passamos, a seguir, a descrever as turmas e o modo como o estudo de caso foi organizado.

\section{Caracterização das turmas}

A primeira turma na qual o estudo de caso foi aplicado tinha um total de 25 estudantes, pertencentes aos cursos de Licenciatura em Química, Bacharelado em Química e Química Tecnológica. O estudo de caso fez parte de uma atividade da disciplina Análise Quantitativa, de 75 horas, que geralmente é cursada no $5^{\circ}$ ou $6^{\circ}$ período do curso e cuja ementa inclui os quatro tipos de volumetrias (ácido-base, precipitação, complexação e oxirredução). A disciplina tem um componente prático e um teórico, sendo que o estudo de caso foi incluído na parte teórica.

A segunda disciplina em que o estudo de caso foi usado é Química Analítica, de 105 horas, disciplina teórico-prática oferecida pelo Departamento de Química para os alunos do $4^{\circ}$ período dos cursos noturno de Farmácia e Biomedicina. Essa turma tinha 52 estudantes frequentes.

\section{Organização do Estudo de Caso}

O estudo de caso foi proposto em conjunto pelas duas professoras que ministravam as disciplinas em que ele foi usado. Na elaboração do caso foram consideradas as características de um "bom estudo de caso" 31 , amplamente descritas por pesquisadores ${ }^{7}$ que usam estudos de caso em sala de aula. No Quadro 1 se encontra o texto entregue aos estudantes que, além de apresentar o caso a ser resolvido (questão 1), solicitava a proposição de um procedimento para determinar o teor de cálcio dos dois medicamentos (questão 2) e a realização de uma atividade de divulgação científica (questão 3), dirigida ao público leigo. Os estudantes também receberam indicação de duas referências bibliográficas ${ }^{17,32}$ para auxiliar no desenvolvimento da atividade. Na disciplina de Análise Quantitativa, o caso foi apresentado aos estudantes durante as aulas de volumetria de complexação, nas quais a professora deu orientações em relação às questões e à bibliografia e combinou com os estudantes o prazo para realização das atividades. Os estudantes foram deixados livres para se organizarem em grupos com até cinco participantes, o que resultou na formação de cinco grupos de 3 a 5 estudantes, uma dupla, e dois estudantes que preferiram realizar a atividade individualmente. $\mathrm{Na}$ disciplina Química Analítica o caso foi entregue por meio da plataforma Moodle. Na aula seguinte à entrega, a professora usou um tempo de 30 minutos para explicar o estudo e tirar as dúvidas. Foram formados 8 grupos com cerca de 6 alunos por grupo. Cada um desses grupos tinha um representante que era responsável por tirar as dúvidas com a professora durante o desenvolvimento da atividade e, ainda, avaliar os colegas do grupo.

Os estudantes das duas turmas tiveram um prazo de três semanas para a entrega do material. Ao final desse prazo as professoras fizeram a avaliação da atividade, sendo que em uma das turmas (Análise Quantitativa) a avaliação foi por escrito, por meio de um questionário online, e na outra (Química Analítica) ela aconteceu durante a aula, com os estudantes opinando em relação ao estudo de caso como ferramenta de aprendizagem. Antes, porém, a professora fez um apanhado dos resultados, por meio de uma apresentação em power point, e apresentou aos estudantes, que participaram ativamente, justificando alguns resultados.

Analisamos, neste trabalho, o material escrito entregue pelos estudantes, as percepções das professoras em torno dessa atividade, bem como as intervenções feitas pelos estudantes durante ofeedback. Algumas falas foram transcritas, usando nomes fictícios, com a intenção de preservar a identidade dos estudantes, de acordo com as orientações do COEP.

\section{RESULTADOS E DISCUSSÃO}

Iniciamos o relato dos resultados apresentando um panorama das atividades vinculadas ao estudo de caso para, em seguida, tratarmos das três proposições feitas. Por fim, analisamos o ponto de vista dos estudantes em relação ao estudo de caso na disciplina que cursavam. 
Quadro 1. Estudo de caso apresentado aos estudantes. No caso da turma de Química, o personagem Júlio é descrito como estudante de Química, em vez de Farmácia

A Dona Helena é uma senhora que faz uso de comprimidos de cálcio, receitados por seu médico para controlar a osteopenia, uma condição bastante comum em sua idade. Sabendo que seu vizinho, o Júlio, é estudante da Faculdade de Farmácia, ela o procurou com uma dúvida:

- Júlio, deixa eu te perguntar uma coisa. Já faz um tempo que eu tomo cápsulas de carbonato de cálcio $500 \mathrm{mg}$, que eu compro em uma farmácia de manipulação. Mas dessa vez, quando fui buscar o medicamento, o frasco veio rotulado como "cálcio quelado" em vez de carbonato de cálcio. E quando eu questionei a atendente da farmácia, ela me disse que é a mesma coisa. Mas não sei... eu fiquei meio desconfiada e estou com medo de tomar esse tal de "cálcio quelado". Será que aí eu devo tomar a mesma dose que o médico recomendou de carbonato de cálcio?

Não sabendo prontamente como responder ao questionamento da Dona Helena, Júlio disse que iria fazer uma busca e procurá-la em breve para dar uma resposta. Como está fazendo estágio em um laboratório de análises químicas, ele resolveu aproveitar para analisar cápsulas dos dois medicamentos para confirmar os teores de cálcio reportados nos rótulos. Além disso, ao ouvir a dúvida de Dona Helena, Júlio ficou preocupado com outras pessoas na rua onde mora, que poderiam ter a mesma dúvida, e resolveu criar um fôlder explicativo sobre essa questão para distribuir aos seus vizinhos.

Imagine que você esteja no lugar do Júlio e queira dar uma resposta correta à Dona Helena e também ajudar a outras pessoas no bairro que estejam em dúvida sobre as diferenças entre os tipos de suplementos de cálcio. Para isso, faça uma pesquisa buscando responder às seguintes perguntas:

1) O médico recomendou à Dona Helena tomar uma cápsula por dia, que corresponde a $1250 \mathrm{mg}$ de carbonato de cálcio, sendo $500 \mathrm{mg}$ de cálcio. Sabendo que o novo medicamento contém $1250 \mathrm{mg}$ de "cálcio quelado" por cápsula, você pode dizer que as doses de cálcio são equivalentes? Considere também a biodisponibilidade dos compostos. $\mathrm{O}$ que você recomendaria à Dona Helena? Apresente os cálculos realizados e justifique sua resposta. 2) Proponha um procedimento para determinar o teor de cálcio nos dois medicamentos utilizando análise volumétrica. Inclua em sua resposta: (a) o tipo de titulação e o titulante a ser utilizado; (b) o pH em que a titulação deve ser feita, com explicação baseada na constante de formação condicional do complexo do cálcio com o titulante; e (c) o indicador escolhido, acompanhado da justificativa para a escolha desse indicador.

3) Crie um fôlder sobre o tema que possa ser utilizado para explicar a questão aos vizinhos do Júlio.

\section{O envolvimento dos estudantes com o estudo de caso: um panorama}

Mesmo estando programado desde o início do semestre, ao receberem o estudo de caso alguns estudantes se mostraram surpresos com o tipo de atividade, o que nos leva a inferir que esse tipo de atividade é pouco comum nesses cursos de graduação. Nas duas semanas que se seguiram à entrega, as professoras solicitaram feedback dos estudantes, tendo um retorno bastante limitado. Na terceira semana, no entanto, os estudantes das duas turmas solicitaram às professoras que estendessem o prazo de entrega em mais uma semana, no que foram atendidos. Foi a partir dessa terceira semana que alguns estudantes procuraram as professoras para tirar dúvidas, principalmente em relação à primeira questão, que envolvia cálculos e também em relação à fórmula química do cálcio quelado.

$\mathrm{O}$ fato de buscarem auxílio das professoras e solicitarem o adiamento da entrega pode ser uma evidência de que os estudantes ainda mantêm características de procrastinadores, ou seja, deixam para depois algo que poderia ser realizado em momento anterior. ${ }^{33}$ A procrastinação tem sido destacada como um fenômeno comum entre jovens e que atinge estudantes universitários. ${ }^{34}$ No entanto, o pouco contato com atividades que exigem deles um envolvimento diferente do habitual, associado à quantidade de disciplinas que cursam ao longo de um semestre e às tantas ações a que esses jovens geralmente estão envolvidos fora da universidade, são variáveis que podem contribuir para que isso aconteça. No caso desses estudantes, o excesso de tarefas associado à pouca habilidade de organização parece ser o fator principal para que se envolvam em uma atividade apenas quando está vencendo o prazo de entrega.

Porém, na terceira e na quarta semanas, o envolvimento na atividade parece ter sido intenso. Em um dos casos em que uma das professoras foi procurada, a estudante discordava da opção do seu grupo em relação ao fôlder a ser entregue. Ela havia produzido outro, diferente do que o grupo havia entregue, e solicitou da professora um feedback em relação a aquele material. O fôlder dessa estudante apresentava uma linguagem mais acessível e era mais colorido e, portanto, mais atrativo para o público leigo, quando comparado ao que seria o fôlder "oficial" do grupo. O fato de o grupo ter optado pelo uso de uma linguagem mais "científica" pode ser um indício de pouco envolvimento com a divulgação científica ao longo do curso.

Ao analisar a presença da divulgação científica em uma amostra de universidades brasileiras, ${ }^{35}$ pesquisadores afirmam que as universidades são geradoras de conhecimento e propulsoras de pesquisa e que, por isso, têm importante papel na divulgação científica e no fortalecimento dessa cultura. Ao entrevistar professores universitários, identificaram um alto grau de importância depositado na divulgação científica presente no discurso, mas com uma prática ainda muito incipiente. É possível que o pouco envolvimento prático com a divulgação científica no interior da universidade tenha contribuído para o resultado relatado pela estudante, ao procurar a professora.

\section{A resolução do caso: como chegaram ao resultado}

Na primeira questão os estudantes deveriam se colocar no lugar do personagem "Júlio" e auxiliar a personagem "Dona Helena" que estava com dúvidas em relação a dosagem de cálcio do seu medicamento. Para isso, eles deveriam apresentar os cálculos usados para identificar o teor de cálcio.

Ao observarmos os relatórios entregues, foi possível perceber que esses estudantes ainda apresentam algumas dificuldades em relação ao entendimento dos conceitos. Para a resolução da questão, eles calcularam a quantidade de cálcio em cada composto para verificar se as quantidades eram equivalentes, usando conhecimentos de estequiometria. Após esse cálculo, eles deveriam considerar os estudos de biodisponibilidade dos medicamentos baseados na referência disponibilizada para consulta. As doses dos dois medicamentos não eram equivalentes e o resultado esperado, em termos de cálculo, se encontra na Tabela 1.

Tabela 1. Quantidade de cálcio em cada composto considerando o comprimido de $1250 \mathrm{mg}$

\begin{tabular}{lcc}
\hline Composto & Carbonato de cálcio & Cálcio quelato \\
\hline Fórmula Química & $\mathrm{CaCO}_{3}$ & $\mathrm{Gly}_{2} \mathrm{Ca} \cdot 2 \mathrm{H}_{2} \mathrm{O}$ \\
Massa molecular $\left(\mathrm{g} \mathrm{mol}^{-1}\right)$ & 100,07 & 224,20 \\
$\begin{array}{l}\text { Massa de cálcio no com- } \\
\text { primido (mg) }\end{array}$ & 500 & 223 \\
Biodisponibilidade $(\%)$ & 24 & 44 \\
Cálcio biodisponível $(\mathrm{mg})$ & 120 & 98 \\
\hline
\end{tabular}

Nos relatórios foram observados três tipos de respostas: os que chegaram à resposta esperada, os que não consideraram as duas moléculas de água ao calcular a massa molar do bisglicinato de 
cálcio e os que erraram os cálculos da massa molar do cálcio quelato e os cálculos de biodisponibilidade. No primeiro agrupamento estão quatro grupos da turma de Farmácia e cinco grupos da Química. Consideramos que esses estudantes estão aptos a novos desafios, uma vez que compreenderam o problema e foram capazes de selecionar procedimentos para resolvê-lo. ${ }^{36}$ No segundo agrupamento estão alguns poucos grupos que cometeram um erro que chamamos de construtivo, ${ }^{36}$ uma vez que bastaria eles tomarem consciência do erro para chegar à resposta correta. Portanto, eles compreenderam o problema e selecionaram os procedimentos necessários, mas cometeram um "deslize". Com esse "deslize", chegaram à conclusão de que as doses dos dois medicamentos eram equivalentes. No terceiro agrupamento está um grupo da Farmácia e dois da Química. Eles não só calcularam erroneamente a massa molar do quelato como também escolheram procedimentos equivocados em termos de biodisponibilidade. Para esse terceiro grupo é necessário uma orientação mais sistemática em termos de conhecimento e de procedimentos.

Vale ressaltar, ainda, que dois grupos de cada turma foram além do que foi solicitado e discutiram os benefícios dos suplementos quelados no que diz respeito ao trato gastrointestinal, inclusive com citação de referências bibliográficas.

\section{As técnicas volumétricas usadas na determinação do teor de cálcio}

Na questão dois os estudantes deveriam propor um procedimento a partir da análise volumétrica, fazendo a descrição do tipo de titulação e do titulante usado, do pH da titulação e do indicador escolhido, acompanhada das justificativas. Com isso, era esperado que os estudantes se utilizassem de uma linguagem mais técnica, normalmente usada em relatórios técnicos, e utilizassem conceitos como equilíbrio de complexação, influência do pH na formação de complexos e volumetria de complexação.

Selecionamos uma das respostas apresentadas para a questão dois, na qual os conceitos solicitados foram usados.

"Em ambos os casos a titulação a ser feita é a titulação de complexação de forma direta, na qual se utiliza o ácido etilenodiaminotetracético (EDTA) como titulante. Para a titulação é necessário o preparo de uma solução do comprimido em água destilada e em solução tampão amoniacal $\left(\mathrm{NH}_{3} / \mathrm{NH}_{4} \mathrm{Cl}\right)$ que irá ajustar o $\mathrm{pH}$ para valores alcalinos $(\mathrm{pH} \sim 10)$, além de agir como um complexante auxiliar para manter os íons metálicos em solução. Embora o quelato de cálcio seja um composto complexado, é possível a titulação de complexação por EDTA, uma vez que o complexo formado com o EDTA será mais estável do que o complexo de cálcio com o aminoácido. $\mathrm{O} \mathrm{pH}$ em que a reação deve ocorrer é entre 8 e 10, pois nessa faixa o $\alpha_{4}$ será maior e com isso terá um valor alto de constante de formação condicional que possibilita a titulação do cálcio. Em virtude dessa alta constante de formação, a reação do ion com o EDTA é mais completa, favorecendo, assim, a complexação do carbonato de cálcio e do cálcio quelato. Se o pH fosse abaixo de 8, o $\alpha_{4}$ e, consequentemente, a constante de formação condicional ( $K f^{\prime}$ ') ficariam menores fazendo com que a reação de formação do complexo não fosse completa nessa faixa e, por conseguinte, impossibilitando uma boa visualização do ponto final. Nota-se também que a forma $Y^{4}$ está completamente desprotonada em $\mathrm{pH}>10$. Sendo assim, a faixa de $\mathrm{pH}$ ideal para formar o complexo mais completo e estável é na faixa de 8-10.”
A resposta anterior foi uma das mais completas dentre as apresentadas, apesar de os estudantes não terem discutido que em $\mathrm{pH}$ acima de 10, quando predomina a forma $\mathrm{Y}^{4-}$, começa a ocorrer a precipitação dos íons $\mathrm{Ca}^{2+}$ na forma de hidróxido. Apesar dessa limitação, consideramos que foram capazes de atender ao que foi solicitado.

Para justificar a melhor escolha do valor de $\mathrm{pH}$ alguns grupos apresentaram o gráfico de distribuição das espécies do EDTA e o gráfico da curva de titulação dos íons $\mathrm{Ca}^{2+}$ em diferentes valores de $\mathrm{pH}$. Apenas dois grupos de cada turma consideraram a constante do complexo cálcio quelato para a realização da titulação com o EDTA. Todos os grupos consideraram a constante de formação condicional para a escolha do valor de $\mathrm{pH}$ a ser utilizado na titulação, com exceção de dois grupos da turma de Química, que fundamentaram sua justificativa apenas na maior disponibilidade de íons $\mathrm{Y}^{4-}$ em meio mais básico. Cabe destacar que alguns estudantes observaram que o melhor $\mathrm{pH}$ seria 12, no entanto, escolheram o pH 10 para a titulação, sem esclarecer que em pH 12 ocorreria a precipitação do cálcio. Esse fato pode ser um indício da dificuldade dos estudantes em relacionar os assuntos desenvolvidos na disciplina. Provavelmente eles ainda tratam os conceitos de forma fragmentada.

Outro ponto que nos chamou a atenção foi a justificativa de alguns grupos para a escolha do indicador, como nos casos apresentados a seguir:

\section{"O indicador deve ter uma transição de cor no $\mathrm{pH}$ do ponto de equivalência. No caso da titulação em análise, um bom indicador seria o Ério-t, que segue essa condição." \\ "Pode ser utilizado o indicador eriocromo T, escolhido pela facilidade de indicação do ponto final e por estar na faixa de pKa \pm 1 da constante de complexação do cálcio"}

Nesses casos, os alunos se confundiram com a escolha de um indicador em uma titulação ácido-base. Apesar de o pH ser importante para a observação da cor do indicador livre, esse não é o único aspecto a ser considerando na escolha de um indicador de complexação. Na aula expositiva (feedback) após a entrega dos estudos de caso, essa questão foi discutida com os estudantes. Esse foi um momento importante para o esclarecimento de dúvidas de conceitos já trabalhados na disciplina, uma vez que nos pareceu claro que a interpretação desses estudantes estava equivocada.

\section{A divulgação científica: o entendimento dos estudantes}

No estudo de caso estava, ainda, a indicação de que os estudantes deveriam produzir um fôlder explicativo a ser entregue aos vizinhos do personagem "Júlio". Esperávamos que eles usassem uma linguagem acessível a um público supostamente leigo ou não acadêmico. Todos os grupos fizeram essa atividade, mediante a entrega de um fôlder impresso ou por meio de um post nas redes sociais. Selecionamos dois exemplos de fôlderes produzidos pelos estudantes.

Um desses fôlderes trazia uma imagem central que apresentava um frasco de medicamento cujo rótulo trazia o íon cálcio acompanhado da pergunta "Você sabe a importância de ingerir cálcio?". Essa imagem era acompanhada de outras quatro que explicavam o que é o cálcio (quadrante 1), os benefícios do cálcio quelado (quadrante 2), os tipos de cálcio disponíveis no mercado (quadrante 3) e outras formas de reposição de cálcio que não por meio de medicamentos (quadrante 4). Na Figura 2 está o quadrante 3, que pode dar uma ideia da linguagem usada pelo grupo.

Na Figura 3 apresentamos outro exemplo de fôlder no qual a linguagem assume uma característica um pouco mais técnica quando comparado ao fôlder da Figura 2. 


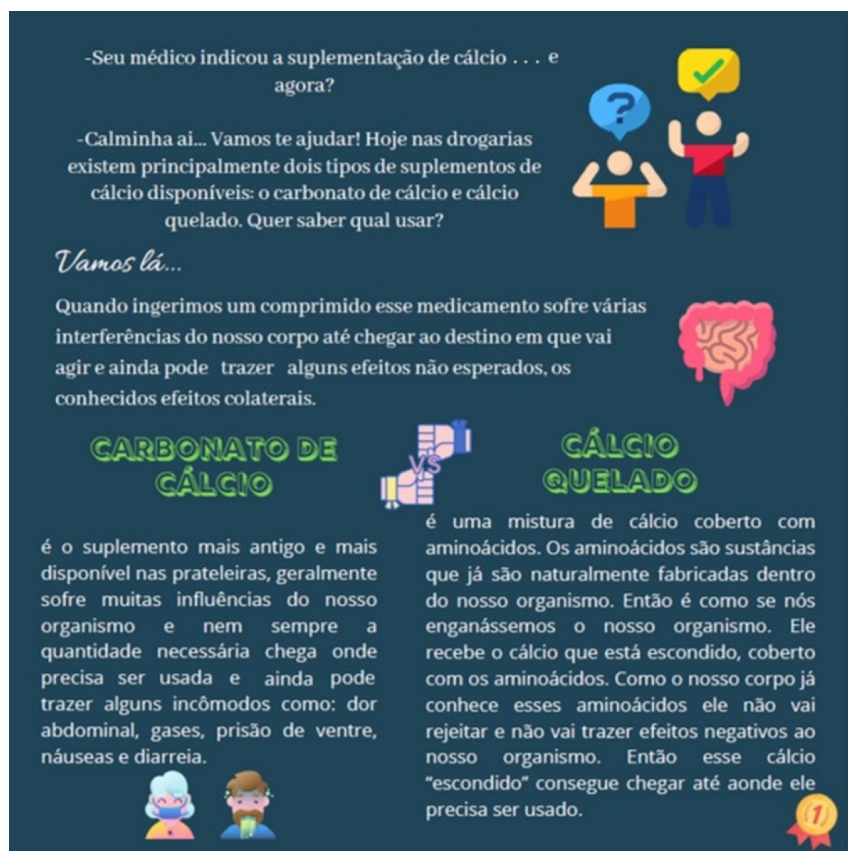

Figura 2. Parte do fôlder produzido por estudantes do curso de Biomedicina

No fôlder da Figura 2, os estudantes discutem a importância da suplementação do cálcio, abordam a questão dos tipos de suplementos disponíveis comercialmente e relatam os benefícios do cálcio quelado. Além disso, eles deixam uma mensagem indicando a importância da prática de atividade física, da alimentação saudável e das idas regulares ao médico (quadrante 4). No segundo material (Figura 3), o grupo chama a atenção para as diferenças entre o carbonato de cálcio e cálcio quelado e destacam a vantagem desse último.

De maneira geral podemos observar diferentes níveis de atenção com a forma de apresentação do material de divulgação. Em um dos fôlderes, por exemplo, os estudantes apresentaram um texto longo seguido de uma representação da estrutura do complexo de cálcio com EDTA, que traz pouca informação compreensível para o público leigo e acaba por ser menos atrativo à leitura. Outros, no entanto, conseguiram transmitir a mensagem de forma mais simples e utilizando recursos visuais mais atrativos. Sabemos que a comunicação com o público leigo é sempre um desafio, principalmente para quem está acostumado com a escrita técnica. Assim, consideramos ser esse um exercício importante para os futuros profissionais, que precisam chegar ao mercado de trabalho preparados para se comunicar com pessoas de outras áreas ou sem formação acadêmica.

\section{O estudo de caso do ponto de vista dos estudantes}

Após a entrega dos relatórios técnicos e do material de divulgação, as professoras organizaram uma síntese das respostas dos grupos, sem identificar a autoria, na forma de feedback, com a intenção de discutir com os estudantes o papel do estudo de caso nas aulas de Química Analítica. Esse feedback mostrou-se como um momento importante para a revisão de alguns conceitos e para a retomada de dúvidas que se mantiveram mesmo após o estudo do conteúdo em sala de aula, como foi o caso do funcionamento dos indicadores usados nas volumetrias de complexação.

Vários pesquisadores ${ }^{37-39}$ têm tratado do feedback como ferramenta de aprendizado, argumentando que um feedback efetivo, frequente e de qualidade pode ser fundamental para a aprendizagem de futuros profissionais. Foi organizado uma apresentação dos resultados em power point contendo os dados descritos no item "b", sem identificar a autoria. Ao fornecermos esse feedback do desempenho dos estudantes nas atividades envolvidas no estudo de caso tivemos várias evidências de entendimentos, a partir da percepção do próprio erro, o que nos leva a argumentar que esse procedimento deveria ser parte da cultura institucional.

Além da discussão em torno dos erros ou equívocos cometidos, os estudantes tiveram a oportunidade de comentar a experiência com o estudo de caso. Podemos afirmar que, entre os estudantes que se pronunciaram, o estudo de caso foi considerado positivo, com afirmações de que aprenderam muito. Selecionamos alguns fragmentos representativos das falas ocorridas após o feedback:

"Deveria ter mais atividades desse tipo! Foi ótimo para enxergamos uma aplicação mais prática dos assuntos que estudamos em sala de aula" (Anderson)

"Foi muito válida essa atividade, alguns conceitos que não ficaram claros para mim foram esclarecidos com a discussão no grupo, durante a realização do trabalho." (Marta)

Sabemos que estudos de caso são mais frequentes em cursos da área da saúde, mas raramente têm sido usados nas disciplinas ofertadas pelo Departamento de Química no qual essa experiência aconteceu. Vários estudantes, assim como Anderson, sugeriram que esse tipo

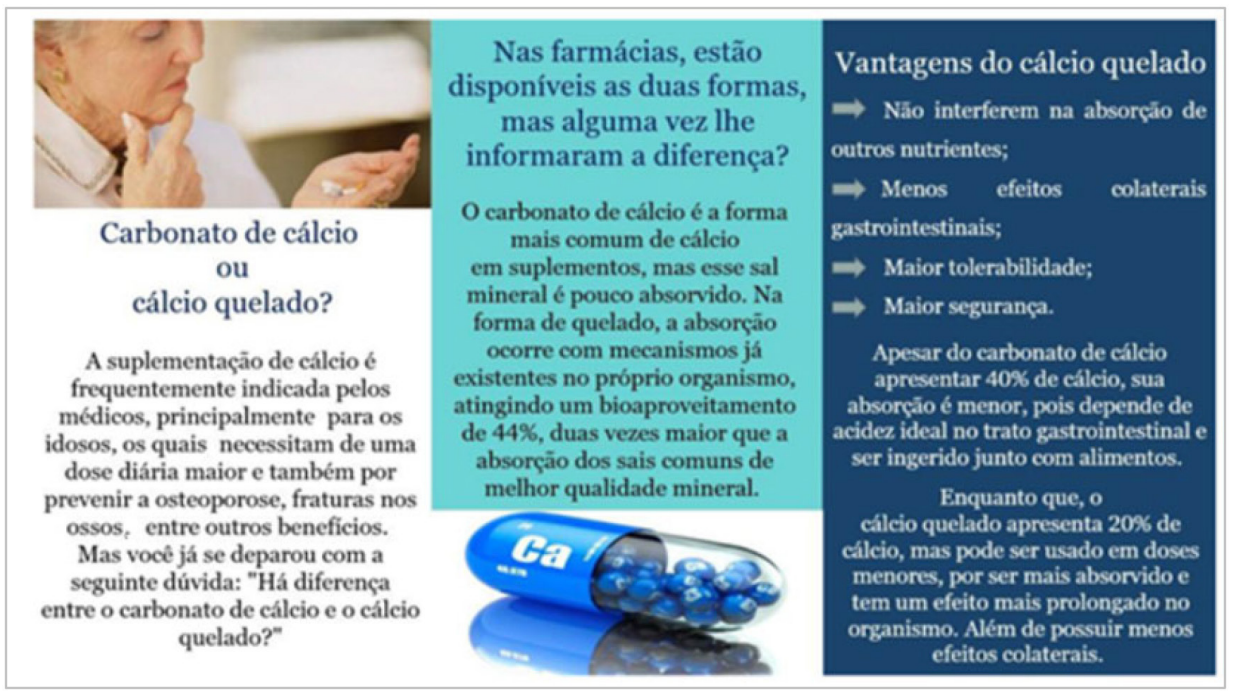

Figura 3. Fôlder produzido por um dos grupos do curso de Farmácia 
de atividade acontecesse com mais frequência e abrangendo outros assuntos, tais como anabolizantes, suplementos, alimentação, entre outros. Parece-nos que esses estudantes se mostraram motivados por terem percebido a relação direta de conceitos da Química Analítica com a sua profissão futura. Como professoras temos clareza dessa intima relação, mas as falas dos estudantes nos deram a sensação de que eles nem sempre são capazes de percebê-la.

Um terceiro estudante fez um comentário que mostra uma abrangência da atividade que não esperávamos ver acontecer. Trata-se da fala de Miguel, da qual transcrevemos um fragmento:

"O estudo de caso nos ajuda a aplicar o conhecimento da sala de aula no dia a dia. Inclusive expliquei o tema do caso em casa! Acho que poderia ser aplicado pelo menos duas vezes no semestre." (Miguel)

Miguel explicou que a conversa se deu com a mãe, que já fez uso de medicamentos à base de cálcio. Argumentamos que o fato de levar o conteúdo de sala de aula para a vivência familiar é um forte indício de valorização dos conhecimentos trabalhados na disciplina. Além disso, esses estudantes trabalharam em grupo, fizeram busca e leituras de publicações e confrontaram as informações encontradas com aquilo que já conheciam do assunto, o que parece ter sido importante para eles. Isso nos leva a afirmar que a proposição de ações pedagógicas que envolvam mais os estudantes devem ter preferência quando comparadas com ações meramente informativas. Os dados obtidos a partir da análise dessa experiência nos mostraram que a nossa contribuição para a formação desses sujeitos tende a ser mais eficaz quando incentivamos a participação ativa dos estudantes e promovemos a direta relação dos conceitos científicos com a profissão futura desses sujeitos.

Algumas limitações também surgiram no momento de avaliação da atividade. Entre elas está o fato de que a busca por informações de qualidade na rede mundial de computadores - Internet - é uma atividade dispendiosa. Porém, a época em que o estudo de caso foi realizado - quase ao final do semestre - certamente foi um grande limitador, já que alguns deles afirmaram ter um tempo restrito para se dedicar ao caso em função de provas avaliativas que aconteceram nessa época. Essa afirmação justifica, em parte, o fato de os estudantes terem se envolvido mais com o caso nas duas semanas anteriores à data de entrega. Com isso, quando perceberam a relevância da atividade, já não dispunham de tempo suficiente para realizar a atividade como gostariam. Porém, acreditamos que esse tipo de atividade pode servir, inclusive, para que eles desenvolvam habilidades de organização dos estudos.

\section{CONCLUSÕES}

Organizamos um estudo de caso envolvendo a ingestão de cálcio a partir da forma inorgânica e do quelato, desenvolvido em duas disciplinas ofertadas pelo setor de Química Analítica do DQ/ UFMG. Neste trabalho analisamos o envolvimento dos estudantes com a atividade proposta, o desenvolvimento de algumas habilidades, tais como o trabalho em equipe e a divulgação científica, e também a relação que fizeram do caso com os conceitos científicos presentes na disciplina.

Até então, nossa experiência como professoras de disciplinas ofertadas pela Química Analítica nos dava, em alguns casos, a sensação de que os estudantes não valorizavam esses conhecimentos e, com isso, não se dedicavam devidamente. Isso poderia estar acontecendo em função de eles não perceberem a aplicação desses conhecimentos $^{1}$ no seu campo de trabalho futuro. Ao analisarmos os dados produzidos a partir do uso do estudo de caso envolvendo a suplementação de cálcio pudemos observar um comportamento bem diverso. Os estudantes se envolveram, destacaram a importância desse estudo, levaram o caso para além da sala de aula e solicitaram que outras atividades semelhantes fossem usadas nas disciplinas.

Pareceu-nos que esses estudantes, ao lidar com o estudo de caso, conseguiram perceber a estreita relação dos conceitos científicos trabalhados na disciplina com o contexto social e, principalmente, com o campo de trabalho futuro. Acreditamos que isso pode ter auxiliado esses estudantes a valorizarem mais a disciplina, embora não tenhamos investigado essa possibilidade.

Destacamos, ainda, o importante papel do professor na condução desse tipo de atividade. Os estudantes não desenvolvem as tarefas de maneira similar, o que pode ser percebido nos resultados distintos apresentados. Isso implica em orientações metodológicas e conceituais no sentido de possibilitar que os grupos consigam atender adequadamente ao que foi solicitado.

Consideramos a inserção do estudo de caso nessas disciplinas como uma experiência positiva. A atividade possibilitou avaliar o aprendizado de maneira mais orgânica, diferente do habitual, que até então era ancorado na aplicação de provas e lista de exercícios. Por sabermos que o estudo de caso não é uma atividade comum nas disciplinas de Química Analítica do ciclo básico e por termos percebido um envolvimento intenso dos estudantes, sentimo-nos instigadas tanto a repetir essa experiência quanto a planejar novos casos, com assuntos e tópicos diferentes desse.

\section{REFERÊNCIAS}

1. Alvim, T. R.; Andrade, J. C.; Quim. Nova 2006, 29, 168.

2. Schunk, D. H.; Learning theories: An educational perspective, $6^{\text {th }}$ ed.; Pearson: Boston, 2012.

3. Leenders, M. R.; Mauffette-Leenders, L. A.; Erskine, J. A.; Writing Cases, $4^{\text {th }}$ ed., London, Canada, 2001.

4. Dowd, S. B. .; Davidhizar, R.; Nurse Educ. 1999, 24, 42.

5. Leal, E. A.; Oliveira, R. L.; Revista Contemporânea de Contabilidade 2018, 15, 69 .

6. Herzer, M.; Menezes, F. M.; Possebon, A. P.; Nunes, F. de L.; Espacios 2016, 37, E-3.

7. Sá, L. P.; Francisco, C. A.; Queiroz, S. L.; Quim. Nova 2007, 30, 731.

8. Sá, L. P.; Quim. Nova 2007, 30, 2035.

9. Pinheiro, A. N.; Medeiros, E. L.; Oliveira, A. C.; Quim. Nova 1996, 33, 1996.

10. Grigoletto, T. L. B.; Fuzari, B. H. C.; R., A. A.; Campos, M. L. A. M.; Gerlach, F. R.; Santos, J. E. T.; Quim. Nova 2012, 35, 1995.

11. Belitz, H.-D.; Grosch, W.; Schieberle, P.; Food Chemistry, $4^{\text {a }}$ ed.; Springer-Verlag: Berlin, Heidelberg, 2009.

12. Nunes Júnior, A.; Revista Técnica do Farmacêutico, 2013, 18.

13. Weaver, C. M.; Heaney, R. P.; In Calcium in Human Health; Weaver, C. M.; Heaney, R. P., Raisz, L. G., eds.; Human Press: Totowa, New Jersey, 2005; pp. 129-144.

14. Straub, D. A.; Nutr. Clin. Pract. 2007, 22, 286.

15. Tang, B. M.; Eslick, G. D.; Nowson, C.; Smith, C.; Bensoussan, A.; Lancet 2007, 370, 657.

16. Pereira, G. A. P.; Genaro, P. S.; Pinheiro, M. M.; Szejnfeld, V. L.; Martini, L. A.; Rev. Bras. Reumatol. 2009, 49, 161.

17. Cook, S.; Chelated Minerals: Addressing Key Challenges in Mineral Supplementation, disponível em http://www.naturalmedicinejournal. com, acessada em dezembro 2020.

18. Heaney, R. P.; Recker, R. R.; Weaver, C. M.; Calcif. Tissue Int. 1990, 46, 300.

19. Yang, S. P.; Tsai, R. Y.; J. Chem. Educ. 2006, 83, 906.

20. Aguilar, F.; Autrup, H.; Barlow, S.; Castle, S.; Crebelli, R.; Dekant, W.; Engel, K.-H.; Gontard, N.; Gott, D.; Grilli, S.; Gürtler, R.; Larsen, J.-C.; 
Leclercq, C.; Leblanc, J.-C.; Malcata, F. X.; Mennes, W.; Milana, M.-R.; Pratt, I.; Rietjens, I.; Tobback, P.; Toldrá, F.; EFSA J. 2008, 718, 1.

21. ANVISA; RDC No. 269 de 22 de setembro de 2005 - Regulamento Técnico sobre a Ingestão Diária Recomendada (IDR) de Proteína, Vitaminas e Minerais 2005.

22. Institute of Medicine; Dietary Reference Intake - Calcium and Vitamin $D$; Ross, A. C., Taylor, C. L., Yaktine, A. L., Del Valle, H. B., eds.; The National Academies Press: Washington, D. C., 2011.

23. Bertotti, M.; Quim. Nova 2011, 34, 1836.

24. Fatibello Filho, O.; Equilíbrio iônico: aplicações em química analítica; EdUFSCar: São Carlos, 2016

25. Terra, J.; Rossi, V.; Quim. Nova 2005, 28, 166.

26. Skoog, D. A.; West, D. M.; Holler, F. J.; Fundamentos de Química Analítica, Ed. traduzida, Pioneira Thomson Learning: São Paulo, 2006.

27. Weigand, W.; J. Chem. Educ. 2000, 77, 1334.

28. Yappert, M. C.; DuPré, D. B.; J. Chem. Educ. 1997, 74, 1422.

29. Kimaru, I. W.; Corigliano, A. T.; Zhao, F.; J. Chem. Educ. 2018, 95 , 2238
30. Simões, G. B.; Badolato, P. V. E. S.; Ignácio, M. D.; Cerqueira, E. C.; J. Chem. Educ. 2020, 97, 522.

31. Herreid, C. F.; J. Coll. Sci. Teach. 1998, 27, 163.

32. Yin, L. H.; Liu, X. P.; Yi, L. Y.; Wang, J.; Zhang, Y. J.; Feng, Y. F.; J. Innov. Opt. Health Sci. 2017, 10, 1650052

33. Burka, J. .; Yuen, L.; Procrastinação, Nobel: São Paulo, 1991.

34. Schuwenburg, H.; In Counseling the Procrastinator in Academic Settings; Schouwenburg, H., Lay, C., Timothy, P., Ferrari, J., eds.; Psychological Association: Washington, D. C., 2004; pp. 3-18.

35. Pessoni, A.; Carmo, V. A. A.; Comunicação \& Informação 2016, 19, 87.

36. Davis, C.; Espósito, Y. L.; Cad. Pesqui. 1990, 71.

37. Borges, M. C.; Miranda, C. H.; Santana, R. C.; Bolela, V. R.; Medicina (Ribeirão Preto) 2014, 47, 324.

38. Pricinote, S. C. M. N.; Pereira, E. R. S.; Rev. Bras. Educ. Med. 2016, 40, 470.

39. Horácio, A. F. G.; Aprender na interação: Efeitos dos estilos parentais na capacidade de aprendizagem com base em feedback, Universidade de Lisboa: Lisboa, 2018. 